\title{
A importância da resposta imune celular na Covid-19
}

Marcelo Henrique Napimoga ${ }^{1}$

Antônio José de Pinho Jr ${ }^{1}$

\section{RESUMO}

As vacinas transformaram a saúde pública, particularmente desde os programas nacionais de imunização que foram estabelecidos e iniciados na década de 1970, no Brasil. Nas ultimas semana, temos visto o aparecimento de variantes emergentes do SARS-CoV-2 (do inglês: Severe Acute Respiratory Syndrome CoronaVirus 2), e as implicações na saúde coletiva ainda não são conhecidas [1].

Estudos in vitro têm destacado a diminuição da neutralização de novas variantes virais por anticorpos produzidos após estímulo vacinal, no entanto, é importante destacar, também, a imunidade mediada por células (linfócitos T) [2]. De fato, as mutações que estão sendo descritas para o SARS-CoV-2, o qual levanta preocupações e indagações acerca da imunidade adquirida de forma natural (após a remissão da doença) ou por meio de uma das vacinas que estão sendo utilizadas ao redor do mundo. Dados do início da doença sugeriram que esta poderia ser comparado a epidemias históricas graves, como a epidemia de influenza de 1918 [3], o que ao passar do tempo se mostrou verdadeira.
Atualmente dúvidas estão sendo levantadas acerca da eficácia das vacinas nestas novas variantes descritas. No entanto, em função do desenvolvimento em tempo recorde das vacinas, ainda não foi possivel estabelecer todos os dados da resposta imunologica de forma que além de destacar o papel da resposta humoral (mediada por anticorpos), é também importante aquela mediada por células (linfócitos T). A partir de estudos de indivíduos com imunodeficiência adquirida, é claro que enquanto pessoas com deficiência na produção de anticorpos aumenta a suscetibilidade à aquisição de infecção, aqueles que possuem deficiência de células T resulta em falha no controle do patógeno após infecção. Por exemplo, indivíduos com deficiência de células T que contaiam o vírus da varicela zoster não são capazes de controlar infecção, se tornando fatal, enquanto os indivíduos com deficiência de anticorpos prontamente desenvolve infecção, mas se recupera da mesma maneira que indivíduos imunocompetentes. Embora a evidência para o envolvimento de células T na proteção induzida por vacina é limitada, isso é provável devido, em parte, às dificuldades de acesso às células $T$ para estudar como apenas o sangue é facilmente acessível,

${ }^{1}$ Faculdade São Leopoldo Mandic, Instituto São Leopoldo Mandic, Área de Imunologia, Campinas/SP, Brasil

Como citar este artigo / How to cite this article

Napimoga MH, Pinha Jr AJ. A importância da resposta imune celular na Covid-19. InterAm J Med Health 2021;4:e202101006 
enquanto muitas células $\mathrm{T}$ residem em tecidos, como nódulos linfáticos [4].

Uma das características principais associadas a uma vacina eficaz contra o SARS-CoV-2 é a de desenvolver anticorpos neutralizantes direcionados à proteína spike. Os anticorpos destinados ao domínio de ligação ao receptor (RBD) de SARS-CoV-2 são fundamentais para impedir o a entrada do vírus nas células. Recentes artigos mostraram que os anticorpos que se ligam ao receptor domínio RBD são críticos para imunidade protetora de longo prazo para COVID-19 infecção e estão associados a uma melhor sobrevida do paciente [5]. Em um artigo recente foi demonstrada que a durabilidade e robustez do anticorpo anti-SARS-CoV-2 dirigidos contra o RBD em 34 pacientes com suspeita ou infectados pelo SARS-CoV-2 apresentaram declínio rápido em anticorpos IgG direcionados ao RBD do SARS-CoV-2. Em razão desse declínio, em sua opinião, "suscitam preocupação que a imunidade humoral contra SARS-CoV-2 pode não ser duradoura em pessoas com doença leve, que compõem a maioria das pessoas com COVID-19 [6].

É importante destacar que as respostas iniciais mediadas por anticorpos IgG emanam dos centros germinativos depois que as células $T$ foliculares ativam as células $B$ virgens para amadurecer em células $B$ ativadas que progridem para células de memória B e plasmócitos produtor de IgG. Os plasmócitos são de curta duração e com dissipação, as respostas lgG iniciais são eliminadas. No entanto, deve-se entender que este não significa que a imunidade diminuiu, uma vez que a persistência de células de memória $B$ e células plasmáticas de longa duração que residem na medula óssea pode reativar respostas específicas do antígeno para o domínio RBD do SARS-CoV-2 se exposto novamente, portanto, a clássica resposta secundária que inicia-se mais rapidamente que a primária, não tem produção de IgM, produz níveis habitualmente mais elevados de IgG e finalmente com anticorpos mais específicos e com capacidade de ligação maior. Além disso, deve ser levado em consideração a importância da memória das células T para o antígeno do SARS-CoV-2, o qual pode resultar em imunidade direta de células $T$ citotóxicas e ajuda para respostas de células B [7].

Em um estudo prévio, foi examinada as respostas das células T CD4+ contra a glicoproteína spike no sangue periférico de pacientes com SARS-CoV-2 positivo, bem como em controles saudáveis. Células T CD4+ reativas contra spike foram detectados em 83\% dos indivíduos infectados. Porém houve também a detecção de células T CD4+ reativas frente a proteína spike no sangue periférico de 35\% dos doadores saudáveis [8]. As células T CD4 + contra spike em doadores saudáveis foram direcionadas contra os epítopos do terminal C da proteína spike e estes epítopos foram identificados em proteínas spike de coronavírus endêmicos que são responsáveis por infecções sazonais do trato respiratório superior. Já contra o SARS-CoV-2 as células T CD4+ reativas de doadores saudáveis também responderam contra a proteína spike de coronavírus endêmicos humanos 229E e OC43. Este dado levanta importantes considerações uma vez que essas células T CD4+ podem exercer respostas imunes cruzada à infecção por SARS-CoV-2, inclusive contra os vários genótipos de COVID-19 [9].

Outro estudo utilizou amostras de sangue coletadas antes da descoberta de SARS-CoV-2 (2015-2018) e demonstraram a presença de células T CD4+ de memória contra 142 epítopos do genoma SARS-CoV2 com afinidade comparável àquelas identificadas em pacientes em recuperação de infecção por SARS-CoV-2, demonstrando a importância das células T CD4+ na criação de respostas imunes duráveis e de reação cruzada a coronavírus humanos, incluindo SARSCoV-2 [10].

Em termos de compreensão da duração e eficácia das respostas das células T para SARS-CoV-2, é muito cedo para determinar isso, pois a longo prazo estudos serão necessários em grandes populações. No entanto, dados apresentados previamente são encorajadores, uma vez que as células $T$ reagiram com múltiplos epítopos no SARS-CoV-2 [11]. Neste ponto, poucas informações estão disponíveis sobre a presença ou duração das células B de memória reativo ao SARS-CoV-2. No entanto, é importante notar que a célula T memória específica para SARS-CoV-1 pode ser detectada 17 anos após o início infecção [12]. Em um preprint publicado em 9 de fevereiro, os pesquisadores descobriram que a maioria das respostas das células T à vacinação contra o coronavírus ou infecção anterior não tem como alvo regiões que foram mutadas em duas variantes recentemente descobertas, incluindo 501Y.V2 [13]. 
A vacina ChAdOx1 nCoV-19 (AZD1222) consiste do vetor de adenovírus símio deficiente para replicação ChAdOx1, contendo a superfície estrutural de comprimento total glicoproteína spike de SARS-CoV-2 (GenBank MN908947). A resposta humoral à proteína spike de SARS-CoV-2 atingiram o pico após 28 dias da inoculação, e a resposta imunológica celular foi induzida em todos os participantes após 14 dias da inoculação. Os anticorpos neutralizantes foram induzidos em todos os participantes após uma segunda dose de vacina. Portanto, após duas doses, uma potente resposta celular e humoral estava presente em todos os participantes do estudo [14]. A presença da imunidade celular parece ser fundamental para a persistência de uma resposta robusta ao vírus em caso de nova exposição, especialmente em relação a essas novas variantes, já que é pouco provável a perda completa de imunidade cruzada quando uma resposta $T$ dependente foi estabelecida. Inclusive a colaboração entre Linfócitos T e B pode ser fundamental para uma imunidade persistente como demonstrada em outros modelos de imunização [15]. Essa informação não está disponível para a outra vacina que está sendo utilizada em nosso país, já que no estudo publicado da Coronavac não foi avaliada a imunidade celular [16]. Contudo, vacinas com vírus inativos, sem a presença de conjugado, não são boas ativadoras de resposta T e podem necessitar de reforço vacinal mais frequente. Extrapolar essa necessidade para indivíduos recuperados de doença, mesmo na forma assintomática, parece um exagero já que jamais tivemos algum dado que comprovasse essa hipótese.

No caso da atual pandemia do vírus SARS-CoV-2, existe a expectativa de que as vacinas já aprovadas irão prevenir o agravamento e hospitalização causada pela Covid-19 e poderá ter um substancial impacto na saúde pública desta doença ao redor do mundo. Nesse momento precisamos entender todo o contexto da resposta imunológica frente as vacinas aprovadas, e se as novas variantes trarão algum impacto na estratégia das vacinas.

\section{REFERÊNCIAS}

1. Freitas ARR, Giovanetti M, Alcantara LC. Variantes emergentes do SARS-CoV-2 e suas implicações na saúde coletiva. InterAm J Med Health. 2021; 4:1-8. https://dx.doi.org/10.31005/ iajmh.v4i.181

2. Graham C, Seow J, Huettner I, et al. Impact of the B.1.1.7 variant on neutralizing monoclonal antibodies recognizing diverse epitopes on SARS-CoV-2 Spike. bioRxiv. 2021 Feb; 3:2021.02.03.429355. https://dx.doi. org/10.1101/2021.02.03.429355

3. Freitas ARR, Napimoga M, Donalisio MR. Assessing the severity of COVID-19. Epidemiol Serv Saude. 2020; 29(2):e2020119. https://dx.doi.org/10.5123/S1679-49742020000200008

4. Pollard AJ, Bijker EM. A guide to vaccinology: from basic principles to new developments. Nat Rev Immunol. 2021 Feb; 21(2):83-100. https://dx.doi.org/10.1038/s41577-020-00479-7

5. Barnes CO, Jette CA, Abernathy ME. SARS-CoV-2 neutralizing antibody structures inform therapeutic strategies. Nature. 2020 Oct 12; 588(7839): 682-687. https://dx.doi.org/10.1038/s41586020-2852-1

6. Ibarrondo FJ, Fulcher JA, Goodman-Meza D. Rapid Decay of Anti-SARS-CoV-2 Antibodies in Persons with Mild Covid-19. N Engl J Med. 2020 Sep 10; 383(11):1085-1087.

7. Jordan SC. Innate and Adaptive Immune Responses to SARS-CoV-2 in Humans: Relevance to Acquired Immunity and Vaccine Responses. Clin Exp Immunol. 2021 Feb; 3(0): 1-11. https://dx.doi.org/10.1111/cei.13582

8. Dan J, Mateus J, Yu K. Immunological memory to SARSCoV-2 assessed for greater than six months after infection. Biorxiv. https://dx.doi.org/10.1101/2020.11.15.383323

9. Braun J, Loyal L, Frentsch M, Wendisch D, Georg P, Kurth F, et al. SARS-CoV-2-reactive T cells in healthy donors and patients with COVID-19. Nature. 2020 Nov; 587(7833):270-274. https:// dx.doi.org/10.1038/s41586-020-2598-9

10. Mateus J, Grifoni A, Tarke A, Sidney J, Ramirez SI, Dan JM, Burger ZC, Rawlings SA, Smith DM, Phillips E, et al. Selective and cross-reactive SARS-CoV-2 T cell epitopes in unexposed humans. Science. 2020 Oct 2; 370(6512):89-94 https://dx.doi. org/10.1126/science.abd3871

11. Peng Y, Mentzer AJ, Liu G, Yao X, Yin Z, Dong D, et al. Oxford Immunology Network Covid-19 Response T cell Consortium; ISARIC4C Investigators, Cornall RJ, Conlon CP, Klenerman $P_{\text {, }}$ Screaton GR, Mongkolsapaya J, McMichael A, Knight JC, Ogg G, Dong T. Broad and strong memory CD4+ and CD8+ T cells induced by SARS-COV-2 in UK convalescent individuals following COVID-19. Nat Immunol. 2020 Nov; 21(11):1336-1345. https:// dx.doi.org/10.1038/s41590-020-0782-6

12. Le Bert N, Tan A, Kunasegaran K. SARS-CoV-2 specific Tcell immunity in cases of COVID-19 and SARS, and uninfected controls. Nature. 2020; 584: 457-462. 
Napimoga $\mathrm{MH}$ et al.

13. Mateus J, Grifoni A, Tarke A, Sidney J, Ramirez SI, Dan JM, et al. Selective and cross-reactive SARS-CoV-2 T-Cell epitopes in unexposed humans. Science. 2020; 370(6512):89-94. https:// dx.doi.org/10.1126/science.abd3871

14. Skelly DT, Harding AC, Gilbert-Jaramillo J, Knight ML, Longet $S$, Brown A, et al. Vaccine-induced immunity provides more robust heterotypic immunity than natural infection to emerging SARS-CoV-2 variants of concern. Preprint at https://www. researchsquare.com/article/rs-226857/v1. 2021.

15. Folegatti PM, Ewer KJ, Aley PK, Angus B, Becker S, BelijRammerstorfer S, et al. Oxford COVID Vaccine Trial Group. Safety and immunogenicity of the ChAdOx1 nCoV-19 vaccine against SARS-CoV-2: a preliminary report of a phase $1 / 2$, single-blind, randomised controlled trial. Lancet. 2020 Aug 15; 396(10249):467-478. https://dx.doi.org/10.1016/S01406736(20)31604-4

16. Malley R, Trzcinski K, Srivastava A, Thompson CM, Anderson PW, Lipsitch M. CD4+ T cells mediate antibody-independent acquired immunity to pneumococcal colonization. Proc Natl Acad Sci U S A. 2005 Mar 29; 102(13):4848-53. https://dx.doi. org/10.1073/pnas.0501254102

17. Wu Z, Hu Y, Xu M, et al. Safety, tolerability, and immunogenicity of an inactivated SARS-CoV-2 vaccine (CoronaVac) in healthy adults aged 60 years and older: a randomised, double-blind, placebo-controlled, phase 1/2 clinical trial. Lancet Infect Dis. 2021 Feb; S1473-3099(20): 30987-7. https://dx.doi. org/10.1016/S1473-3099(20)30987-7 